\title{
Poliglobulia e hidronefrosis de riñón en herradura
}

\author{
A. Gómez-Ferrer Lozano, J.A. Navarro Antón, M.J. Mola Arizo, A.C. Polo i Peris \\ Servicio de Urología. Hospital Lluís Alcanyís de Xàtiva, Valencia.
}

Actas Urol Esp 2005; 29 (4): 414-415

\section{RESUMEN}

POLIGLOBULIA E HIDRONEFROSIS DE RIÑÓN EN HERRADURA

Presentamos el caso clínico de un paciente en el que se asoció eritrocitosis e hidronefrosis del hemirriñón derecho de un riñón en herradura. El paciente presentaba hidronefrosis masiva avanzada secundaria a obstrucción pieloureteral ocupando todo el hemiabdomen derecho. Después de la nefrectomía la masa eritrocitaria descendió a valores normales. La poliglobulia secundaria puede ser debida a una producción inadecuada de eritropoyetina y se ha descrito en asociación con patología renal de diversa naturaleza, incluida la hidronefrosis, pero en muy escasas ocasiones en relación a hidronefrosis de un riñón en herradura.

Palabras clave: Poliglobulia. Riñón en herradura. Hidronefrosis.

\section{ABSTRACT}

ERYTHROCYTOSIS RELATED WITH HYDRONEPHROSIS IN A HORSESHOE KIDNEY

We report a case of a man with erythrocytosis secondary to hydronephrosis in a right horseshoe kidney. The patient had an advanced hydronephrosis because of ureteropelvic junction obstruction occupying the right hemiabdomen. Following nephrectomy of the right kidney eritrocyte count returned to normal values. Secondary polyglobulia may be due to increased erytropoietine values and has been related in some patients with renal diseases such as hydronephrosis, but very rarely in association with hydronephrotic horseshoe kidney.

Keywords: Erythrocytosis. Hydronephrosis. Horseshoe kidney.

$\mathrm{L}^{2}$ os riñones en herradura constituyen la anomalía de fusión más frecuente. Esta alteración anatómica predispone a una mayor frecuencia de patologías obstructivas y litiásicas, principalmente, siendo la estenosis de la unión pieloureteral la alteración más frecuentemente descrita.

La presencia de un recuento elevado de masa eritrocitaria puede ser de causa primaria, denominada policitemia vera, o reactiva y secundaria a otras patologías y/o situaciones fisiológicas en las que exista una alta demanda de oxígeno o una producción inadeacuda de eritropoyetina ${ }^{1}$.

La poliglobulia secundaria puede aparecer en varios procesos renales tales como hidronefrosis, patología quística, tumoral y vascular, tanto en relación con un aumento demostrado de eritropoyetina como sin él.

\section{CASO CLÍnICO}

Se presenta un varón de 26 años con clínica de hipo persistente, dispepsia y sensación de plenitud postprandrial. Entre sus antecedentes destaca una laparotomía exploradora a los 14 años por un traumatismo abdominal, del cual desconocemos datos por haberse realizado en otro centro. En la exploración se objetivó una ocupación de todo el hemiabdomen derecho por una masa de consistencia elástica, a tensión, indolora y mate a la percusión que sobrepasaba la línea media. Se realizó un hemograma de rutina que puso de manifiesto un recuento de $7,13 \times 10^{6}$ hematies, $20.5 \mathrm{~g} / \mathrm{dl}$ de hemoglobina y hematocrito de $65.9 \%$, con cifras similares en el preoperatorio inmediato. 
La ecografía abdominal mostró una hidronefrosis masiva del riñón derecho. La TAC abdominal confirmó el diagnóstico de ectasia pielocalicial masiva con prácticamente ausencia de cortical, que ocupaba la totalidad del hemiabdomen derecho, sobrepasando la línea media hasta contactar con el polo inferior del riñón izquierdo, sugestivo de riñón en herradura (Fig. 1)

Se practicó, por lumbotomía, nefrectomía derecha de un gran riñón hidronefrótico secundario a estenosis de la unión pieloureteral, cursando el postoperatorio sin incidencias. El estudio anatomopatológico informó de riñón hidronefrótico con atrofia cortical marcada.

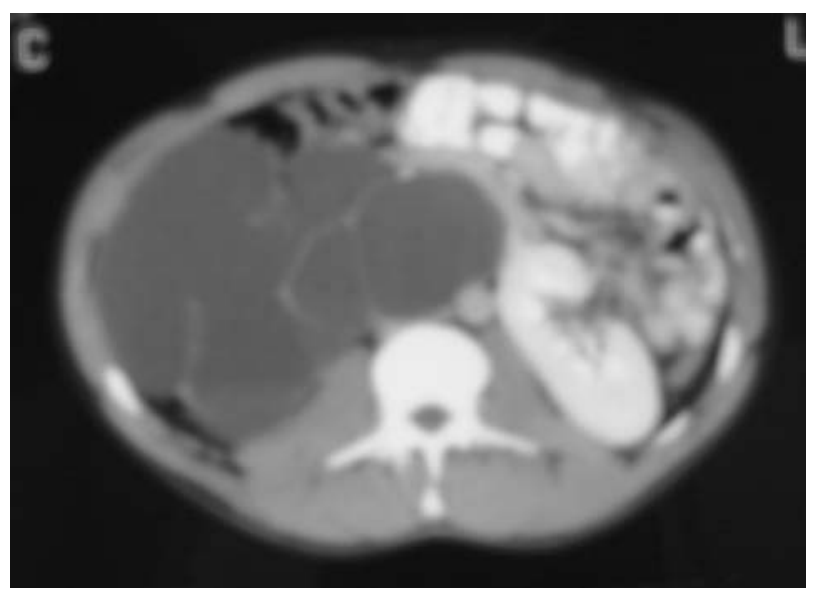

Figura 1: T.A.C.: Hidronefrosis masiva de riñón en herradura derecho.

El hemograma al segundo día de la cirugía presentaba una Hemoglobina de 15 g/dl, 4,6 millones de eritrocitos y 43,7\% de hematocrito.

Se practicó otro hemograma 10 meses después evidenciándose una normalización del recuento eritrocitario (Tabla 1 ).

Tabla 1

Hemogramas previo y posteriores a nefrectomía

\begin{tabular}{lccc}
\hline & $\begin{array}{c}\text { Recuento de } \\
\text { eritrocitos } \\
\text { (x10-6) }\end{array}$ & $\begin{array}{c}\text { Hemoglobina } \\
\text { (mg/dl) }\end{array}$ & $\begin{array}{c}\text { Hematocrito } \\
\text { (\%) }\end{array}$ \\
\hline $\begin{array}{l}\text { Pre-Nefrectomía } \\
2 \text { días post- }\end{array}$ & 7,13 & 20,5 & 65,9 \\
nefrectomía & 4.6 & 15,0 & 43,7 \\
$\begin{array}{l}10 \text { meses post- } \\
\text { nefrectomía }\end{array}$ & 4.6 & 14,5 & 41,5 \\
\hline
\end{tabular}

\section{DISCUSIÓN}

La poliglobulia puede ser primaria, consecuencia de un trastorno hematológico -Policitemia Verao secundaria a situaciones de hipoxia (altitud, patología cardiopulmonar), como manifestación paraneoplásica y secundaria a patología renal (neoplasias, poliquistosis, glomerulonefritis, trasplante renal, estenosis de la arteria renal e hidronefrosis). En estas últimas dos situaciones se considera que existe un mecanismo de producción elevada o anómalo de eritropoyetina.

La asociación de hidronefrosis y poliglobulia ha sido descrita en escasas ocasiones, pero solo hemos encontrado en la literatura dos casos de riñón en herradura hidronefrótico y eritrocitosis reversible tras la nefrectomía ${ }^{2,3}$.

El desarrollo de poliglobulia en el contexto de enfermedades renales se ha relacionado con una producción aumentada de eritropoyetina. Aunque nosotros no determinamos los niveles de eritropoyetina ni en plasma ni en el líquido de hidronefrosis, hemos podido constatar una normalización hematológica tras la nefrectomía, lo que determina la etiología de la eritrocitosis de este paciente. No obstante, la determinación de eritropoyetina en los dos únicos casos descritos mostró discrepancia en este valor, siendo normal en uno y elevada en otro, pero como en nuestro caso, normalizándose el recuento eritrocitario en los dos pacientes tras la nefrectomía y manteniéndose a lo largo del tiempo, lo que determina la relación etiológica de este proceso.

\section{REFERENCIAS}

1. Cervantes Requena F, Rozman C. Policitemia Vera. Pag 1677- 1680 En: Medicina Interna. Farreras Rozman. 12 $2^{\mathrm{a}} \mathrm{ed}$. Ediciones Doyma, Barcelona 1992.

2. Valero Puerta JA, Jiménez Gonzalo FJ, Medina Pérez M, Valpuesta Fernández I, Sánchez González M, López Rodríguez L. Poliglobulia e hidronefrosis en riñón en herradura. Arch Esp Urol 1999;52(8):890-892.

3. Bayle RR, Shand BI, Walker RJ. Reversible erythrocytosis in a patient with hydronephrotic horseshoe kidney. Nephron 1995;70:104-105.

Dr. A. Gómez-Ferrer Lozano

Servicio de Urología

Hospital Lluís Alcanyís de Xàtiva.

Carretera Xàtiva - Silla Km. 2

46800 Xàtiva (Valencia.)

(Trabajo recibido el 26 de julio 2004) 